\title{
UMA PESQUISA DOCUMENTAL SOBRE A INCLUSÃO ESCOLAR DE PESSOAS COM DEFICIÊNCIA: DA GÊNESE AO ATENDIMENTO EDUCACIONAL ESPECIALIZADO
}

\author{
Josiane de Almeida Trevisani ${ }^{1}$, Moacir Pereira de Souza Filho ${ }^{2}$ \\ Universidade Estadual Paulista - UNESP, Programa de Pós-Graduação em Educação, Presidente Prudente, SP. E-mail: \\ jositrevisani@yahoo.com.br, moacir@fct.unesp.br.
}

\section{RESUMO}

Os profissionais da educação não estão preparados para enfrentar deficiências intelectuais e motoras, de alunos com necessidades educacionais especiais, fazendo com que eles não tenham um atendimento educacional especializado. Esta pesquisa teve por objetivo, apresentar elementos fundamentais para refletir sobre a inclusão escolar. A modalidade da pesquisa caracteriza-se como uma pesquisa documental (bibliográfica e histórica). Realizou-se um levantamento histórico sobre a educação inclusiva, sobre a legislação e sobre os referenciais que possibilitaram o entendimento do tema em questão. Os resultados foram divididos basicamente em cinco tópicos para que pudéssemos refletir sobre a educação inclusiva. O trabalho permitiu inferir que, a inclusão não deve ficar restrita as adaptações do espaço físico e ao direito a matricula, mas deve ser oferecida uma educação de qualidade, com uma equipe multidisciplinar de profissionais de diversas áreas do conhecimento.

Palavras-Chave: Educação Inclusiva. Atendimento Educacional Especializado. Sala de Recursos.

\section{A BIBLIOGRAPHIC RESEARCH ON THE SCHOOL INCLUSION OF DISABLED PEOPLE: FROM THE BIRTH TO SPECIALIZED EDUCATIONAL CARE}

\begin{abstract}
The education professionals are not prepared to face intellectual and motor deficiencies of students with special needs, so that they do not have a specialized educational service. This research aims to present fundamental elements to reflect on school inclusion. The research modality is characterized as a documentary research (bibliographical and historical). A historical survey was made on inclusive education, on the legislation and on the references that made possible the understanding of the subject in question. The results were divided basically into five topics so that we could reflect on inclusive education. The study allowed to infer that inclusion should not be restricted to adaptations of physical space and the right to enrollment, but a quality education should be offered, with a multidisciplinary team of professionals from several areas of knowledge.
\end{abstract}

Keywords: Inclusive Education. Specialized Educational Assistance. Inclusive Space. 


\section{INTRODUÇÃO}

O nascimento de uma criança com algum tipo de deficiência, provoca nos pais uma sensação de insegurança. Segundo Aranha (2006, p. 11), receber um filho com deficiência provoca na família (e principalmente nos pais), sensações emocionais características de situações de perda: negação, rejeição, raiva, culpa e não aceitação. Da mesma forma, essa sensação de insegurança atinge também os profissionais que nem sempre estão preparados para enfrentar deficiências intelectuais e motoras, características de alunos com necessidades educacionais especiais. Sendo assim, infelizmente, muitos alunos que deveriam ter o seu direito reconhecido, acabam se tornando "uma mera decoração" no fundo da sala de aula, sem ter o atendimento educacional especializado.

Neste sentido, este estudo investigativo tem por objetivo central, apresentar elementos fundamentais para refletir sobre a inclusão escolar de alunos com necessidades educativas especiais, e analisar como é realizado o atendimento educacional especializado com os alunos que tem dificuldades, para que ocorra a efetivação de sua aprendizagem.

Esta pesquisa, caracteriza-se por um estudo de cunho bibliográfico, que traz à luz discussões e apontamentos teóricos em torno da educação inclusiva. O processo investigativo vai buscar elementos no processo histórico, a fim de compreender sua gênese e os desdobramentos que culmina em um Atendimento Educacional Especializado (AEE), cuja dinâmica que se estabelece entre o professor da sala de recursos e o professor da sala comum, que são fundamentais para compreender os caminhos da inclusão nas escolas.

Diante do exposto, este estudo apresenta basicamente duas questões de pesquisa visa elucidar: (i) Qual é a importância de desenvolver um trabalho eficaz com as crianças que necessitam de um atendimento educacional especializado (seja ele qual for)? (ii) como o atendimento em sala de Atendimento Educacional Especializado (AEE) contribui no sucesso do processo de ensino aprendizagem, em um contexto escolar, onde realmente a criança será incluída, e não apenas integrada num canto da sala de aula como um objeto de "decoração". Portanto, os resultados alcançados pela pesquisa pretende compreender o processo de inclusão de pessoas com deficiências.

\section{METODOLOGIA}

A modalidade da pesquisa caracteriza-se como uma pesquisa documental (bibliográfica e histórica). Os pesquisadores fizeram um levantamento histórico sobre as primeiras concepções sobre a educação inclusiva e sobre os referenciais que possibilitaram o entendimento do tema em questão.

Segundo Lehfeld e Barros (2007), seu objetivo é adquirir conhecimento visando resolver ou contornar um problema posto, a partir do emprego predominante de informações advindas do material gráfico. É relevante levantar e selecionar conhecimentos de materiais confiáveis e já catalogados em bibliotecas e na internet. É necessário seguir os passos norteadores da investigação. Eles são basicamente: (i) tema-problema - para delimitar o objeto de investigação; (ii) hipótese de trabalho - algo hipotético que guia nosso olhar para o problema apresentado; (iii) levantamento bibliográfico - localização dos referenciais sobre o assunto a ser investigado; (iv) documentação, registro, organização e interpretação dos resultados.

\section{RESULTADOS}

Os resultados da pesquisa foram obtidos por um estudo a respeito do tema "educação inclusiva" e foram divididos basicamente em cinco tópicos para que pudéssemos fazer uma discussão e refletir sobre a educação inclusiva:

\section{a) UMA BREVE HISTÓRIA DA EDUCAÇÃO INCLUSIVA}


Pouco se dispõe de registros sobre como se caracterizava a relação entre a sociedade e a deficiência na vida cotidiana da antiguidade. Porém, pode-se encontrar na bíblia e na literatura da época, passagens que nos possibilitam supor qual era o tratamento dado a essas pessoas, com limitações funcionais e com necessidades diferenciadas: a grande maioria era abandonada ao relento, era exterminada, ou ainda, vivia à margem da sociedade. Acreditava-se que a pessoa com deficiência era demoníaca, e que Deus havia castigado a família com o nascimento de um ser com deficiência.

Segundo kirk e Gallagher (1996 apud GONILE e SANTOS, 2002), na Idade Média com a difusão do cristianismo, as pessoas mentalmente afetadas ou defeituosas, não eram mais exterminadas da sociedade, pois eram tidas como criaturas divinas.

No século XVI, começaram a surgir novas ideias referentes à natureza orgânica da deficiência, mas foi no século XVII que ocorreram vários avanços na Medicina, fortalecendo a tese da organicidade, ampliando-se a compreensão da deficiência como processo natural. A partir daí, conventos e asilos, seguidos pelos hospitais psiquiátricos, constituíram-se em locais de confinamento para as pessoas com deficiências, com a finalidade de oferecer uma educação a parte. Contudo, Foi somente na segunda parte do século XX, que a pessoa com deficiência foi considerada cidadã, com direitos e deveres, baseada na ideologia da normalização, que defendia a necessidade de inserir a pessoa com necessidades educacionais especiais na sociedade, com o objetivo de ajudá-la a adquirir as condições de vida de uma pessoa "sem deficiência", ou seja, passou a ter um caráter assistencialista e caritativo.

\section{b) LEIS QUE CONTRIBUÍRAM PARA UM NOVO OLHAR SOBRE A EDUCAÇÃO INCLUSIVA}

Inserir as pessoas com algum tipo de deficiência na sociedade e não mais escondê-las é o que defendia a Declaração Universal dos Direitos Humanos, adotada e proclamada pela Resolução 217 da Assembleia Geral das Nações Unidas, em 10 de dezembro de 1948. Em seu artigo primeiro, ela estabelece igualdade, dignidade e direitos entre todas as pessoas, "sem distinção de qualquer espécie, seja de raça, cor, sexo, etc." (ONU, 1978).

Outras atitudes coletivas colaboraram para a discussão do papel da sociedade para a inclusão das pessoas com necessidades educacionais especiais. Entre elas podemos citar:

- A Declaração de Salamanca, uma conferência mundial sobre Necessidades Educativas Especiais, realizada em Salamanca (Espanha), entre 07 e 10 de julho de 1994, que foi organizada pela UNESCO em cooperação com o Ministério de Educação e Ciência da Espanha.

As repercussões da Conferência e de seus escritos foram inúmeros, marcando a permanência de discussões sobre o atendimento educacional oferecido a esses cidadãos com necessidades educacionais especiais, sem deixar de reconhecer a necessidade e urgência de ser o ensino ministrado à todas as crianças, jovens e adultos que dependem de uma aula adaptada. $O$ verdadeiro divisor de águas, a Declaração de Salamanca, resultou de constante jogo de forças entre representantes de mais de noventa e dois países, que indiscutivelmente mantiveram uma posição contrária a exclusão escolar (ANGELUCCI, 2002).

A Declaração de Salamanca repercutiu de forma significativa, sendo incorporadas as políticas educacionais brasileiras. Pode-se dizer que o conjunto de recomendações e propostas por essa Declaração foi guiado pelos seguintes princípios: (i) Independente das diferenças individuais, a educação é direito de todos; (ii) Toda criança que possui dificuldades de aprendizagem pode ser considerada com necessidades educacionais especiais; (iii) A escola deve adaptar-se as especificidades dos alunos, e não os alunos as especificidades da escola; (iv) o ensino deve ser diversificado e realizado num espaço comum a todas as crianças.

Podemos citar também, duas declarações que o Brasil é signatário, são elas: 
- A Declaração Mundial sobre Educação para todos, realizada na cidade de Jomtien (Tailândia) no ano de 1990, que reconhece que a educação é de suma importância para o progresso pessoal e social, e indica vários objetivos a serem alcançados pelas nações;

- A Declaração de Guatemala, realizada em 2011, que foi uma convenção Interamericana, que teve por objetivo prevenir e eliminar todas as formas de discriminação contra as pessoas com deficiência e proporcionar sua plena integração à sociedade.

Com respaldo no trabalho de Ferreira e Ferreira (2011), apresentaremos a seguir um panorama da inclusão no Brasil:

Em 1978, uma emenda à constituição que trata do direito da pessoa com deficiência, assegurou melhorias da sua condição social e econômica, priorizando a educação especial e gratuita.

Nas décadas de 80 e 90, foram realizados vários Congressos Mundiais de Educação defendendo a inclusão, entre eles é importante ressaltar que em 1985, a Assembleia Geral da ONU, recomendava o ensino de pessoas com deficiência no sistema regular, e posteriormente a Constituição de 1988, veio respaldar e garantir esse atendimento.

Diversos foram os documentos que foram produzidos durante esse processo de avanços e conquistas do movimento da inclusão e do ensino especial em particular, segundo Ferreira e Ferreira (2011, p. 20) [...] o que se chama a atenção é a pluralidade normativa utilizada, que muitas vezes chegava a ser contraditória [...], já que nos diferentes documentos o conceito de inclusão era abordado em diferentes perspectivas, podendo ser a perspectiva da inclusão social, racial, educacional e de políticas públicas. Como sendo um fenômeno sociocultural recente, a inclusão exigiu um esforço, para a caracterização e compreensão das suas peculiaridades.

\section{c) PANORAMA A INCLUSÃO BRASILEIRA}

No Brasil, a Educação Especial apareceu pela primeira vez com a LDB 4.024/61, ressaltando que a educação dos excepcionais, naquilo que fosse possível, deveria enquadrar-se no sistema geral de educação. Já na Lei de $n$ o 5.692/74, foi previsto o tratamento especial para os alunos que apresentarem deficiências físicas, mentais e os superdotados.

Contudo, pôde-se constatar que o processo de inclusão passou a ser efetivamente discutido a partir da Lei de Diretrizes e Bases da Educação Nacional, Lei de no 9394/96, o que oficializou, através do capítulo $V$, artigos 58 a 60, os passos para que as instituições de ensino se adaptassem a estrutura física e adequassem os currículos, em especial os de licenciatura, para que pudessem atender nas salas de aula do ensino regular, os alunos com Necessidades Educacionais Especiais.

Dessa forma, no Brasil, elaboraram-se diversas propostas e leis a fim de normatizar a inclusão, entre elas podemos citar: (i) Resolução CNE/CEB 4/2009 que institui diretrizes operacionais para o atendimento Educacional Especializado na Educação Básica, modalidade Educação Especial; (ii) Lei de no 10.172, de 9 de janeiro de 2011 que trata da aprovação do Plano Nacional de Educação; (iii) Decreto de no 3298, de 20 de Dezembro de 1999 - que regulamenta a Lei no 7.853, de 24 de Outubro de 1989, sobre a política Nacional para a Integração da Pessoa com Deficiência, dentre outras.

\section{d) RELEVÂNCIA DO ATENDIMENTO EDUCACIONAL ESPECIALIZADO (AAE)}

Nessa perspectiva de oferecer ao aluno com Necessidades Educacionais Especiais a inclusão ao ensino regular, foram criadas pelo MEC, as salas de AEE (atendimento educacional especializado), que deveriam ser frequentadas pelos alunos em horário contrário a das aulas na sala regular.

A proposta do MEC era ter uma sala de recurso em cada escola, mas quando isso não fosse possível, as escolas poderiam se dividir em polos e os alunos seriam direcionados, para a sala mais próxima e mais apropriada para a sua necessidade educacional. Essas salas têm como finalidade preparar o aluno para as atividades da vida diária. Por exemplo, um aluno surdo que precisa 
utilizar a LIBRAS para se comunicar, na sala de recurso ele vai aprender a linguagem de sinais, e na sala regular é onde ele vai usar o que aprendeu no caso a LIBRAS.

É evidente que o processo de inclusão teve avanços significativos, mas não podemos deixar de constatar que ainda existem muito a se fazer, muitos paradigmas a serem quebrados, estamos vivendo um processo de mudança de mentalidade, incluir é lei, recusar um aluno com deficiência, segundo a Lei Federal de no 7.853, de 24 de outubro de 1989, em seu artigo. 8 é "crime". Mas incluir verdadeiramente, não basta apenas cumprir o que diz a lei. Trata-se da mudança de mentalidade citada acima, trata-se de estarmos comprometidos em realizar esta inclusão, como peças fundamentais para o desenvolvimento global dos alunos, seja ele um aluno com Necessidades Educacionais Especiais ou não.

Em conformidade com os artigos de lei, o A.E.E. (Atendimento Educacional Especializado) tem o dever de disponibilizar os serviços e apoio nas classes comuns da rede regular de ensino, bem como, a capacitação suficiente aos professores e as orientações quando necessário.

e) SALA DE RECURSOS E A PROMOÇÃO DA EDUCAÇÃO INCLUSIVA

A diferença essencial entre Sala de Recursos e Sala de Recursos Multifuncionais se dá no que se refere ao alunado, a estrutura da sala e a formação do professor.

A sala de recursos multifuncionais atende alunos: cegos, surdos, com deficiência intelectual, enquanto a sala de Recursos "comum", não atende alunos cegos e surdos, pois estes são atendidos em outros programas específicos para suas necessidades educacionais especiais.

A sala de recursos "comum" atende alunos com deficiência intelectual e também os que apresentam transtornos funcionais específicos (transtorno de déficit de atenção -TDHA e hiperatividade e com distúrbios de aprendizagem). No que se refere a essa sala de recursos "comum", a escola onde ela está implantada é quem deve prover os materiais necessários; assim, geralmente, eles se resumem em materiais pedagógicos muito simples, sendo que muitos deles são confeccionados pelas próprias professoras dessas salas ou comprados pela própria escola. Já as salas de recursos multifuncionais recebem muitos materiais, inclusive computadores e mobiliário adaptado, do governo federal.

\section{DISCUSSÃO}

O movimento mundial pela educação inclusiva é uma ação política, cultural, social e pedagógica, desencadeada em defesa do direito de todos os alunos estarem juntos, aprendendo e participando, sem nenhum tipo de discriminação. A educação inclusiva constitui um paradigma educacional fundamentado na concepção de direitos humanos, que conjuga igualdade e diferença com valores indissociáveis, e que avança em relação à ideia de equidade formal ao contextualizar as circunstancias históricas da exclusão dentro e fora da escola.

Ao reconhecer que as dificuldades enfrentadas nos sistemas de ensino evidenciam a necessidade de confrontar as práticas discriminatórias e de criar alternativas para superá-las, a educação inclusiva assume espaço central no debate acerca da sociedade contemporânea e do papel da escola na superação da lógica da exclusão. A partir dos referenciais para a construção de sistemas educacionais inclusivos, a organização de escolas e classes especiais passa a ser repensada, implicando uma mudança estrutural e cultural para que todos os alunos tenham suas especificidades atendidas.

A escola, historicamente, se caracterizou pela visão da educação que delimita a escolarização como privilégio de um grupo, uma exclusão que foi legitimada nas políticas e práticas educacionais reprodutoras da ordem social. A partir do processo de democratização da escola, evidencia-se o paradoxo inclusão/exclusão quando os sistemas de ensino universalizam o acesso, mas continuam excluindo indivíduos e grupos considerados fora dos padrões homogeneizadores da escola. 
A partir da visão dos direitos humanos e do conceito de cidadania fundamentado no reconhecimento das diferenças e na participação dos sujeitos, decorre uma identificação dos mecanismos e processos de hierarquização que operam na regulação e produção das desigualdades. Essa problematização explicita os processos normativos de distinção dos alunos em razão de características intelectuais, físicas, culturais, sociais e linguísticas, entre outras estruturantes do modelo tradicional de educação escolar.

A educação especial se organizou tradicionalmente como atendimento educacional especializado substitutivo ao ensino comum, evidenciando diferentes compreensões, terminologias e modalidades que levaram à criação de instituições especializadas, escolas especiais e classes especiais. Essa organização, fundamentada no conceito de normalidade/anormalidade, determina formas de atendimento clínico-terapêuticos fortemente ancorados nos testes psicométricos que, por meio de diagnósticos, definem as práticas escolares para os alunos com deficiência/necessidades educacionais especiais.

Por muito tempo perdurou o atendimento em que a educação especial, organizada de forma paralela à educação comum, seria a forma mais apropriada para o atendimento de alunos que apresentavam deficiência ou que não se adequassem à estrutura rígida dos sistemas de ensino. Essa concepção exerceu impacto duradouro na história da educação especial, resultando em práticas que enfatizavam os aspectos relacionados à deficiência, em contraposição à sua dimensão pedagógica.

A educação inclusiva, a partir do reconhecimento e valorização da diversidade como fator de enriquecimento do processo educacional, tem provocado mudanças na escola e na formação docente, propondo uma reestruturação da educação que beneficie todos os alunos. A organização de uma escola para todos, prevê o acesso à escolarização e ao atendimento às necessidades educacionais especiais.

No paradigma da educação inclusiva, resultante do conceito de sociedade também inclusiva, os sistemas e instituições sociais são adaptados às necessidades de todas as pessoas e não o contrário, quando os indivíduos estão sujeitos a se adaptarem às exigências do sistema. Nesse processo, a formação dos professores é fundamental para que a aprendizagem esteja centrada no potencial de cada aluno, de forma que uma incapacidade para andar, ouvir, enxergar, ou um déficit no desenvolvimento não seja classificado como falta de competência para aprender e nem a causa de desistência dos alunos estudarem.

Muitas práticas têm violado os direitos das crianças e adolescentes nas escolas. Os educadores dizem não estarem preparados para receber alunos com necessidades educacionais especiais; as escolas não oferecem acessibilidade; as famílias desistem da escolarização de seus filhos porque muitas escolas não aceitam crianças com deficiência; a escolarização de alunos com deficiência mental se mantém no âmbito da Educação Infantil; os alunos abandonam as escolas que não respondem às suas necessidades.

Paradoxalmente a esse processo, experiências positivas afirmam que muitas crianças são incluídas, com sucesso, nas escolas de ensino regular, evidenciando o compromisso da gestão da escola na construção de um projeto pedagógico que contemple as diferenças e a organização de espaços para a realização do atendimento educacional especializado.

\section{CONCLUSÃO}

Ao encerrar o presente trabalho, revisando a literatura sobre inclusão escolar, constatou-se que a inclusão trouxe para as escolas alunos com todos os tipos de necessidades educacionais especiais. Verificou-se, que por ter uma exigência de leis, as escolas efetivam as matriculas dos alunos encaminhados, porém o atendimento educacional especializado que já acontece, está longe de suprir as grandes necessidades dos incluídos. Acontece a inclusão social, mas a inclusão que prepara os alunos para serem futuros cidadãos preparados, caminha lentamente. Pode-se 
constatar que há ações concretas fazendo com que aconteça a efetivação da inclusão escolar, seja em nível local ou mundial.

Sobre o atendimento educacional especializado, que seria o ideal, o sonho dos educadores para incluir os alunos com necessidades educacionais especiais, constatou-se que está muito no início nas instituições de ensino em geral. Acredita-se que ações simples podem afetar o curso da inclusão escolar, construindo uma ética que se reflita em novas formas de compreender e tratar com o alunado de inclusão.

Por fim, conclui-se que a inclusão não deve ficar restrita as adaptações do espaço físico e ao direito a matricula, mas deve ser oferecida uma educação de qualidade com uma equipe multidisciplinar de profissionais de diversas áreas do conhecimento.

\section{REFERÊNCIAS}

ARANHA, M. S. F. Integração Social do Deficiente: Análise Conceitual e Metodológica. Temas em Psicologia, número 2, 1995, p. 63 - 70. Ribeirão Preto, Sociedade Brasileira de Psicologia.

BRASIL. Constituição (1988) Constituição: República Federativa do Brasil. Brasília, DF: Senado Federal, 1988.

BRASIL. Decreto - Lei 2.208, de 17 de abril de 1997. Regulamenta o § 2ㅇ do Art. 36 e os Arts. 39 a 42 da Lei no 9.394, de 20 de dezembro de 1996, que estabelece as diretrizes e bases da educação nacional. 1997. Disponível em:<http://www.planalto.gov.br/ccivil_03/decreto/D2208.htm>>. Acesso em: 1 maio de 2017.

BRASIL Ministério da educação. Secretaria de Educação Especial (SEESP). Política educacional de educação na perspectiva da educação inclusiva. Brasília: MEC, 2008.

BRASIL. Ministério da Educação. Resolução CNE/CEB n. 02, de 11 de setembro de 2001. Disponível em: <http://portal.mec.gov.br/cne/arquivos/pdf/CEB0201.pdf>. Acesso em: 04 de maio 2017.

BRASIL. Ministério da Educação. Secretaria de Educação Especial. Diretrizes Nacionais para a Educação Especial na Educação Básica. Brasília: MEC/SEESP, 2001.

BRASIL. Ministério da Educação. Secretaria de Educação Especial. Salas de Recursos Multifuncionais: espaço para atendimento educação especializado. Brasília: 2006.

BRASIL. Ministério da Educação. Secretaria de Educação Especial. Parecer 017/2001. Brasília: MEC/SEESP, 2001.

BRASIL. Presidência da República. Secretaria Especial dos Direitos Humanos. Coordenadoria para a Integração social da pessoa portadora de Deficiência. Convenção sobre os Direitos das Pessoas com Deficiência. Brasília: SICORDE, 2007.

BRASIL. Política Nacional da Educação Especial na Perspectiva da Educação Inclusiva. Disponível em www.mec.gov.br. Acesso em 11de Maio de 2017.

Diretrizes Nacionais para a Educação Especial na Educação Básica. Resolução CNE/CEB 2/2001. Diário Oficial da União, Brasília, 14 de setembro de 2001. Seção 1E, p. 39-40. Disponível em: http://portal.mec.gov.br/cne/arquivos/pdf/CEB0201.pdf>. Acesso em: 10/05/2017. 
FERREIRA, M. C.; FERREIRA, J. R. Sobre inclusão, políticas públicas e práticas pedagógicas. São Paulo: Autores associados, 2011.

LEHFELD, N. A. S.; A. J. S. BARROS. Fundamentos da metodologia científica, 3a. ed., São Paulo: Pearson Prentice Hall, 2007.

MANTOAN, M. T. E. Inclusão Escolar. O que é? Por quê? Como fazer? São Paulo: Moderna, 2003. MEC: SALAS DE RECURSOS MULTIFUNCIONAIS. http://www.mec.gov.br/ Autor: presidente da república - MEC ministério educação continuada. Acesso 23 de abril de 2017.

SASSAKI, R. K. Terminologia sobre deficiência na era da inclusão. Revista Nacional de Reabilitação, São Paulo, v.5, n.25, p. 5-14, 2002.

UNESCO. Declaração de Salamanca. Adaptada pela Conferência Mundial sobre Necessidades Educativas Especiais: acesso e qualidade. Salamanca, Espanha, 1994.

WALLON, Henri. A evolução psicológica da criança. São Paulo: Martins Fontes, 2007. 